\title{
Alvorecer da imprensa de rua e sobre a rua no Brasil
}

\author{
Mônica Celestino
}

Resumo

Uma parcela dos cerca de 1.200 sem-tetos de Salvador (BA) participa, desde março de 2007, de uma experiência pioneira no jornalismo baiano: o jornal de rua $A u$ rora de Rua. A população de rua participa diretamente da produção do tablóide bimestral e comercializa exemplares do veículo, dentro de um projeto que propicia a reinserção social de quem sobrevive em espaço público e, ainda, busca estimular o debate sobre o tema na sociedade. A publicação aplica um conceito já consolidado na Europa - o de imprensa de rua. Este paper relata a experiência soteropolitana, no contexto nacional e internacional, e busca estabelecer relações entre seus procedimentos produtivos e os princípios do "jornalismo cívico", a partir da memória, da pesquisa bibliográfica e da análise do jornal.

Palauras-chave:

Jornal de rua, Aurora da Rua, Jornalismo cívico

\section{The rise of street press and the street life in Brazil}

\section{Abstract}

Sobre a autora Doutoranda em História Social pela Universidade Federal da Bahia (UFBA), professora na

Faculdade Social da Bahia (FSBA). monicacs75@hotmail.com
Part of the 1,200 homeless people living in Salvador, Bahia, Brazil, participate, since March 2007, in a pioneering experience in the journalism in Bahia: the street paper called Aurora de Rua (Street Sunrise). The homeless people participates directly of the production and the selling of this tabloid printed once every two months. It is part of a project to promote social reinsertion of the ones who survive in a public space and it also tries to provoke a debate about the subject in the society. The paper applies a concept already solid in Europe - the one of street press. This article reports the experience in the city of Salvador in national and international context and it tries to establish relations between its ways to produce and the principles of 'civic journalism', from memory, from related bibliography and from the paper analysis.

Key words:

Street paper, Aurora da Rua, Civic journalism 
Entre 1,5 mil e 2,4 mil indigentes, migrantes e outras pessoas sem habitação e em situação de risco e vulnerabilidade social constituem a população de rua de Salvador (BA), a terceira capital mais populosa do país com cerca de 2,7 milhões de habitantes, conforme estimativa de Prefeitura Municipal local (A Tarde, 2007). A maioria tem idade entre 45 e 55 anos, é do sexo masculino e está em situação de pobreza extrema, ou seja, tira seu sustento da rua e não tem abrigo. Em geral, eles tornam-se excluídos devido a fatores como divergências familiares, desemprego, ocorrência de distúrbios psiquiátricos e/ou abuso de drogas.

Ainda são parcos os dados no Brasil sobre o tema, porém uma avaliação inicial do Ministério do Desenvolvimento Social, de abril de 2005, indica que sobrevivem em vias públicas entre $0,6 \%$ e $1 \%$ dos brasileiros dos grandes centros urbanos. As cidades com mais casos seriam Salvador (BA), São Paulo (SP), Fortaleza (CE), Niterói (RJ), Belo Horizonte (MG), Campina Grande (PB), Maringá (PR) e Porto Alegre (RS). A capital paulista tem a maior quantidade (10.394 pessoas, o equivalente a 0,96\% da população total), enquanto as demais teriam mais de 800 pessoas cada uma.

Com este volume e o fortalecimento de ações pelo exercício da cidadania no mundo, surge em vários países, inclusive no Brasil, uma nova segmentação da imprensa - o street paper. Pode-se afirmar que há três grupos desses jornais e revistas, distinguidos a partir do foco de atuação. O primeiro propicia somente a geração de renda para homeless, por meio da venda de exemplares da publicação. O segundo proporciona a participação deste grupo social no processo produtivo, por meio da oferta de oficinas e do estímulo à escrita, à fotografia e à ilustração ministradas por profissionais de jornalismo e áreas afins. O terceiro articula as oportunidades de envolvimento tanto na produção quanto na comercialização. Todos, entretanto, primam por discutir fatos relacionados ao cotidiano, às dificuldades, às demandas e às conquistas desta fatia da sociedade.

O objetivo é proporcionar visibilidade, opção de trabalho remunerado, subsistência e, por conseguinte, reinserção na sociedade à população de rua, que está suscetível ao abuso de drogas lícitas e ilícitas, à exploração sexual e da mão-de-obra e à violência urbana e, em geral, é vitimizada por preconceito e exclusão, fato motivado, sobretudo, pela equivocada associação das más condições sociais e econômicas à marginalidade. Sobre isto, a International Network of Street Papers (INSP) sintetiza:

Since the end of the 1980s, street papers have provided an immediate solution to an urgent need, enabling poor and homeless people to earn a dignified income and help themselves to rebuild their lives and find a place in society. The street papers are a long-term tool
Com o

fortalecimento de ações pelo exercício da cidadania no mundo, surge em vários países, inclusive no Brasil, uma nova segmentação da imprensa - o street paper 
for social transformation that connect people across harmful social barriers and advocate for the needs and rights of people living in poverty. They reach over 32 million readers worldwide every year. (INSP, 2007.)

Concebida, produzida e comercializada com participação de semteto londrinos, a revista The Big Issue (Brum, 2004a) consolida-se como um dos mais relevantes títulos desse segmento no mundo. Fundada em 1991, no Reino Unido, a publicação conquistou prestígio junto à sociedade, inclusive personalidades, e passou a circular em outros países. Até estimulou a concepção, em 1991, da INSP (Cantarino, 2005), entidade sediada em Glasgow, Escócia, e que reúne cerca de 80 veículos de 37 países. Ao menos três brasileiros integram-na. São eles: o jornal Boca de Rua, de Porto Alegre (RS), constituído em 2001; a revista Ocas, da Organização Civil de Ação Social (Ocas), criada em 2002 em São Paulo (SP) e no Rio de Janeiro (RJ); e o tablóide Aurora da Rua $a^{1}$, em circulação comercial desde 2007, em Salvador (BA). Cada sócio tem autonomia para desenvolver seu projeto e, juntos, os associados envolvem 250 mil pessoas (INSP, 2007).

Este texto busca fazer o relato da experiência do Aurora e articular suas práticas aos princípios característicos daquilo que estudiosos do campo denominam de jornalismo cívico. Para tanto, utiliza-se a memória, a pesquisa bibliográfica e a análise das edições do primeiro ano do jornal. As intenções são tanto registrar os procedimentos produtivos do periódico quanto contribuir para a reflexão acerca da aplicação do conceito de jornal de rua no Estado, considerando-se que este é pioneiro no Nordeste brasileiro.

\section{Aurora da Rua e outros street papers brasileiros}

O gaúcho Boca de Rua (Cantarino, 2004), fundado pelas jornalistas Rosina Duarte e Clarinha Glock (da Alice - Agência Livre para Infância, Cidadania e Educação) em 2001, é pioneiro no Brasil e visa facultar o acesso de pessoas excluídas à mídia e subsidiar o exercício da cidadania, através da difusão e problematização do cotidiano, das idéias e das ações da população de rua de Porto Alegre (RS). O periódico é trimestral e tem tiragem de 10 mil exemplares.

Elaborado com a participação de cerca de 30 sem-teto - a maioria analfabeta - e profissionais de comunicação, o jornal é desenvolvido em três etapas. Primeiro, a equipe discute com a comunidade nas ruas o tema do número e planeja os textos (escritos à mão), as fotografias e ilustrações a serem providenciados. Depois, a população de rua elabora o conteúdo e os jornalistas editam o material. Por fim, cada sem-teto comercializa cerca de 30 unidades por semana e recebe parte do valor cobrado aos clientes. Se o autor do texto é analfabeto, os profissionais fazem a transposição da linguagem oral para a escrita.

${ }^{1} \mathrm{O}$ veículo não tem seu nome na lista de filiados da organização divulgada pelo site oficial, mas já está associado à entidade. 
Meses após o surgimento do Boca, em julho de 2002, a Organização Civil para Ação Social (OCAS, 2008) lançou a revista mensal Ocas (OCAS, 2008; BRUM, 2004ª), que aborda temas culturais, políticos e sociais ligados ao universo dos sem-teto, reserva espaço para manifestação deles (embora a produção seja de responsabilidade de jornalistas) e possibilita a autonomia financeira e inserção social de cerca de 50 pessoas (os vendedores) por vez. Mais de 1.200 - maiores de 18 anos - já se beneficiaram em cinco anos. Cento e cinqüenta mil exemplares em policromia são comercializados todo mês no Rio de Janeiro e em São Paulo, onde fica a sede da Ocas. O vendedor fica com $2 / 3$ do preço cobrado ao leitor ( $\mathrm{R} \$ 3$ ). Além do percentual aferido com as vendas, a publicação mantém-se com a negociação de anúncios publicitários, mas ainda há dificuldade para captação de investidores.

Quatro anos depois, a imprensa de rua e sobre a rua chegou à Bahia. Em dezembro de 2006, começou a circular pela capital baiana um número-piloto do jornal bimestral Aurora da Rua, elaborado pela comunidade de sem-teto e distribuído para disseminação da proposta entre formadores de opinião, representantes de organizações não-governamentais e líderes católicos. Três meses depois, a equipe editou o número um e conseguiu encartar gratuitamente 120 mil exemplares, no dia 25 de março de 2007, em A Tarde, diário de maior circulação do estado. Outros veículos cobriram a ação, dando visibilidade ao periódico.

O Aurora tem como diferencial o envolvimento da população de rua em todas as fases do processo produtivo e de comercialização. Ou seja, essas pessoas atuam na vendagem, são personagens de matérias e contribuem na discussão de pautas e na preparação do conteúdo, através de oficinas de texto e de arte promovidas em espaços públicos como praças e largos por voluntários, entre os quais jornalistas profissionais como Ingrid Campos (jornalista responsável e editora), Fernanda Souza (designer) e Antônio Moreno (assessor de imprensa). Ao todo, há 15 redatores (incluindo voluntários) e 32 vendedores (entre albergados, sem-teto, ex-sem-teto e membros da comunidade da Trindade), todos maiores de 18 anos de idade.

Cada edição surge a partir da escolha pela equipe dos temas a serem abordados. Em seguida, o grupo dirige-se a locais de grande aglomeração em Salvador (como Largo de Roma, Praça da Piedade e Mercado Modelo) e propõe às pessoas que falem, escrevam ou desenhem sobre aqueles assuntos, em um ambiente informal. Os voluntários ficam na retaguarda, apenas anotando os depoimentos, para posterior redação com base nas técnicas jornalísticas e divulgação sob a identificação "Texto Coletivo". Alguns, que dominam a escrita ou alguma arte, produzem o seu próprio conteúdo. Na fase final, todo o material é analisado pelo Conselho Editorial, que tem participação da população de rua; editado; encaminhado para a pro-
Em dezembro de 2006, começou a circular pela capital baiana um númeropiloto do jornal bimestral Aurora da Rua, elaborado pela comunidade de sem-teto 
gramação visual e impressão; e distribuído pelos vendedores em vias de grande circulação e universidades, por exemplo.

O jornal reúne notícias, perfis, artigos, cartas, mensagens, poesias, fotografias e desenhos sobre fatos, idéias e ações da população de rua, sobretudo de Salvador e sob o ponto de vista dela mesma. Ele enfoca temas como educação, saúde, habitação, preconceito, violência, cultura e arte, ou seja, tanto a rotina árida em praças, pontes, viadutos, edificações abandonadas e calçadas quanto a beleza e criatividade dos sem-teto. Busca valorizar o ser humano, através de uma linguagem híbrida, entre a norma culta e a linguagem coloquial. Portanto, o periódico procura "tornar visível e audível, a face e a voz daqueles que muitas vezes são pouco vistos e pouco ouvidos na sociedade" (Aurora da Rua, 2007), mas sem tratá-los como vítimas de uma situação social determinante e sem chance de reversão. O coordenador e membro do Conselho Editorial do projeto, Irmão Henrique Peregrino, explica a opção:

Escolhemos falar da rua dentro do jornal, a partir de um ângulo diferente do que A Tarde, Correio (da Bahia) falam, em que o povo de rua aparece em condição de miséria. A gente sabe da miséria, mas sabe também de toda beleza, das coisas boas que existem na rua. Por isso fazemos oficinas de texto para falar disso. (Peregrino, 2007.)

O tablóide tem oito páginas coloridas. A capa destaca o tema da principal matéria de cada número, através de manchete, uma chamada e uma fotografia ou ilustração aberta em duas ou três colunas, e apresenta, também, a logomarca e três chamadas para outras matérias com ou sem fotografias e ilustrações. A página dois é dedicada ao editorial, à seção "Cartas da Rua" (com correspondências encaminhadas à redação ou comentários transcritos de leitores e da comunidade de rua), ao Código de Conduta dos vendedores e ao expediente. Já a página três tem textos, fotografias e ilustrações da lavra de estudantes e profissionais de jornalismo ou transcritos por eles, a partir das oficinas promovidas nas ruas.

As páginas centrais (4 e 5) são voltadas para a seção "Matéria de Capa”, com textos, fotografias e ilustrações de jornalistas ou assinados como de autoria coletiva por serem feitos nas oficinas. A página seis traz duas seções: a "Aurora Notícias", constituída por notas ilustradas com fotografias ou desenhos sobre a população de rua, de caráter local, nacional e internacional e, ainda, a "Deus na Rua", com uma parábola sobre aventuras do Criador pela cidade concebidas pelo francês Henrique Peregrino. A seção propõe-se a levar uma mensagem de esperança aos leitores, o que é evidenciado por seu conteúdo e pela cor azul utilizada como plano de fundo.

A sétima página apresenta um perfil e fotografias de um "morador de rua" com história de vida singular, redigido por outra sem-teto, 
a Maria Lúcia Pereira (Costa, 2007). Alcoólatra em recuperação, a escritora cursou o ensino médio e faz a coluna "Brilho da Aurora" desde que se revelou em uma das oficinas de texto do projeto. Por fim, vem a contracapa, espaço congrega as seções "Arte Rua", com material produzido nas oficinas de artes ou obras de pessoas que sobrevivem em via pública, como poesias e desenhos, e "Tirinhas da Rua", com episódios da história em quadrinhos Aurora e Turminha da Rua. De autoria de Marcos Queiroz, eles versam sobre o cotidiano de uma mulher, Aurora.

Vencedor do Salão de Design da Diretoria de Artes Visuais 2007 da Fundação Cultural do Estado da Bahia, na categoria Produto, o projeto gráfico de Fernanda Pereira é inovador e explora ilustrações, espaços em branco e impressão em policromia no papel-jornal de 65 gramas. Assim, facilita a compreensão e aceitação do periódico pelo leitor, que já está habituado à leitura de impressos com tais características. A intenção (Peregrino, 2007) é que o tablóide valha quanto custa e possa gerar orgulho no vendedor, fortalecendo-o para interagir com o cliente na condição de prestador de serviço (e não de pedinte) em uma relação de respeito mútuo. A partir de então, como ocorre em outros street papers, ele amplia sua rede de relacionamentos, ganha auto-estima, conquista independência financeira e, quando consegue emprego ou trabalho com melhores condições e moradia, cede a vaga a outro. $\mathrm{O}$ site oficial explica a estratégia:

Ao ler o jornal, o leitor é convidado a um novo olhar sobre a rua e seu povo. O jornal espera provocar uma mudança de atitude no leitor. Não quer ser apenas veículo de informação, mas também agente de transformação de uma realidade desumana. Ao adquirir o jornal, o comprador participa de uma transformação da sociedade. Ele gera inclusão social. Não compra apenas um produto comercial, mas um produto social. Ele faz parte do projeto e sua fidelidade na compra do jornal garante o sucesso do projeto. (Aurora da Rua, 2007.)

A maior parte da tiragem de 10 mil exemplares é comercializada exclusivamente por pessoas em situação de rua, por $\mathrm{R} \$ 1,00$ cada, em Salvador e Região Metropolitana. Deste valor, 25\% são destinados ao custeio e à manutenção do noticioso e 75\% são reservados ao jornaleiro, 14 vezes a mais do que os $5 \%$ habitualmente repassados pelos periódicos locais aos seus distribuidores. Como estratégia de divulgação, uma cota segue para Belo Horizonte (MG), onde são organizadas oficinas de leitura por movimentos sociais; São Paulo (SP), para disseminação pela Pastoral de Rua; e outros municípios brasileiros, por meio de assinatura.

Como não há venda de espaço para anúncios publicitários, para evitar a associação indiscriminada da imagem de empresas à proposta social, toda a receita do Aurora é obtida exclusivamente com 
a venda direta e as assinaturas. Neste caso, pessoas físicas e organizações adquirem o jornal para distribuição entre seus amigos, clientes e colaboradores, sem terem sua imagem veiculada pelo tablóide. Em outubro do ano passado, seis instituições e mais de 200 assinantes pessoais de 23 estados já haviam aderido à iniciativa, assegurando a sua auto-sustentação (Peregrino, 2007).

Ao ingressar no projeto, cada jornaleiro passa por uma semana de treinamento sobre vendas e cidadania, recebe uniforme (colete, boné e bolsa com logomarca) e crachá de identificação, e ganha dez exemplares cuja venda vai assegurar a aquisição de novas unidades posteriormente. Depois, tem acesso às oficinas; a sessões quinzenais com psicólogo; a atividades para recuperação do abuso de álcool e drogas ilícitas; à orientação e ao auxílio para resgate do vínculo com a família e emissão de documentos; e à capacitação para negócios, através de encontros mensais com empresários. Participa de reuniões para troca de experiências e resgate da auto-estima, baseadas no princípio da ajuda mútua. Se houver demanda específica (ocorrência de doenças, falta de documentos, dependência química etc.), recebe atendimento em uma rede de parceiros do terceiro setor. Em contrapartida, compromete-se em respeitar um código de conduta, aprovado pelo grupo, que traz regras como a obrigatoriedade de trabalhar sóbrio.

O impresso soteropolitano é produzido por sem-teto (Brigham, 2007; Costa, 2007; Lima, 2007) que vivem na setecentista Igreja da Trindade, na região de Água de Meninos, na Cidade Baixa, em Salvador. A comunidade da Trindade é formada por, em média, 40 adultos, idosos e crianças e mantém-se por meio de de doações e um sistema de auto-suficiência e co-responsabilidade nas decisões, nas tarefas do dia-a-dia e no sustento através da venda de artesanato, de material reciclável e do jornal. Cada um contribui com quanto pode e considera suficiente para uma espécie de caixa comunitária, pelo prazer de colaborar. É uma rede de ressocialização por meio do acesso à alimentação, moradia, saúde, educação, lazer e qualificação profissional para ingresso no mercado formal; é uma rede pelos direitos preconizados pela Constituição Federal do Brasil de 1988.

A principal regra de conduta na Trindade é o respeito mútuo, o que tem se mostrado eficaz mesmo entre aquelas pessoas desacostumadas ao cumprimento de deveres e horários. A adaptação ocorre aos poucos. Os princípios foram disseminados pelo monge francês Henrique Peregrino, fundador do grupo, membro do Conselho Editorial do Aurora e autor das parábolas da seção "Deus na Rua". Após fazer doações de alimentos, cobertores e roupas em grandes cidades brasileiras, "Irmão Henrique" chegou em 1990 à capital baiana, onde foi acolhido no Centro por Pirá, um migrante natural do município de Ipirá, na região semi-árida do estado, que sobrevivia defronte à Igreja da Piedade. Em seguida, afastou-se para
Ao ingressar no projeto, cada jornaleiro passa por uma semana de treinamento sobre vendas e cidadania, recebe uniforme e crachá de identificação, e ganha dez exemplares 
percorrer outras localidades do Nordeste, mas, em 2000, retornou e instalou a Trindade com autorização da Arquidiocese de Salvador. Formado em Filosofia e Teologia, foi delatado e preso pela Polícia Federal por viver ilegalmente no país e relatou essa trajetória no livro Peregrinando ao Encontro da Trindade (Editora Paulinas).

Aurora da Rua, Boca da Rua e Ocas têm princípios em comum, que os credenciam como imprensa de rua. Garantem trabalho, renda, aproximação da população marginalizada com as letras e artes e interação com a sociedade; propiciam acesso à mídia a quem até então estava à margem dela; e difundem conteúdo capaz de contribuir para o desenvolvimento de políticas públicas para o pleno exercício da cidadania. Como preconiza a International Network of Street Papers (INSP, 2007), são independentes e promovem a reinserção social de excluídos através do envolvimento direto desta população com o projeto. Nos três, os sem-teto vendem exemplares, recebem uma fração do valor arrecadado e voltam a conviver com grupos sociais diversos, em uma relação de respeito mútuo deflagrada a partir do comércio.

Diferem, portanto, de jornais, revistas e murais sobre a população de rua, mas sem necessariamente o envolvimento dela no seu processo produtivo, de comercialização e/ou distribuição. No Brasil, há empreendimentos bem-sucedidos neste sentido e o pioneiro é $O$ Trecheiro, da Rede Rua de Comunicação, de São Paulo (SP). Elaborado por profissionais, ele busca dar visibilidade, em suas quatro páginas, às condições de vida de pessoas em situação de rua e a movimentos sociais dedicados ao combate da exclusão social no município de São Paulo e em outras cidades brasileiras. Desde 1991, já foram veiculados 160 números. Sediado no bairro do Brás, em São Paulo, tem tiragem de 5 mil unidades por mês, está disponível na internet (www.rederua.org.br) e mantém-se com a venda direta e de assinaturas. Surgida nos anos de 1980, a Rede Rua promove comunicação, documenta e assessora iniciativas populares.

\section{Jornalismo e cidadania}

O contexto social e político do Brasil propicia a propagação de iniciativas desta natureza. Desde os anos 1970, organizações do terceiro setor ${ }^{2}$ e ações contra a discriminação e por políticas públicas afirmativas das chamadas minorias ${ }^{3}$ começaram a se multiplicar no país, e a filosofia da responsabilidade social e do voluntariado passou a ser disseminada na sociedade brasileira. Beneficiaram-se, para tanto, da revisão do papel do Estado e do amadurecimento do próprio setor, que passou a enfocar a melhoria da qualidade de vida da população, através da interação com o mercado e o Estado, em detrimento das ações estritamente político-ideológicas. Estima-se que o Brasil tenha cerca de 280 mil organizações não-governamentais (ONGs), associações e cooperativas com finalidades e atuação

${ }^{2} \mathrm{O}$ termo terceiro setor é aplicado ao conjunto de organizações da sociedade civil de origem privada, gerindo recursos de diversas fontes, mas sem fins lucrativos, a exemplo de fundações, associações e das organizações da sociedade civil de interesse público. Organizações desta natureza atuam junto às comunidades menos privilegiadas, suprindo carências culturais, fisiológicas e psicossociais. $\mathrm{O}$ primeiro setor representa a estrutura governamental e o segundo, a iniciativa privada com fins lucrativos. Ver Garcia; Pinheiro; Santa Bárbara, 003. p. 77-87.

${ }^{3}$ As minorias são tomadas aqui não como grupos minoritários da população, em relação à quantidade de representantes, mas como grupos constrangidos em favor de outros, independente de suas dimensões. Exemplos são crianças e adolescentes, idosos, negros e homossexuais. 
em segmentos diversos. Aproximadamente 6\% estão sediadas na Bahia, de acordo com dados do Instituto Brasileiro de Geografia e Estatística tabulados pela Associação Brasileira de ONGs.

Em concomitância, o conceito de jornalismo cívico ou jornalismo público (civic journalism or public journalism) dissemina-se no mundo, inclusive no Brasil, como um dos principais referenciais para o exercício do jornalismo com responsabilidade social, a partir dos Estados Unidos. Em 1990, ele foi delineado por David Merrit, editor de Wichita Eagle (estado do Kansas), e, em seguida, foi implementado entre os estadunidenses, sobretudo por meio do Pew Center for Civic Journalism, da Filadélfia, propagando-se gradualmente por outros países. À época, visava reverter a queda da venda de jornais, promover a recuperação econômica dos veículos e estimular o voto (que é facultativo nos Estados Unidos).

O conceito de jornalismo cívico é polêmico. Afinal, todo jornalismo deve ser voltado para o bem público e propiciar o exercício pleno da cidadania pelos seus públicos, o que, a princípio, dispensaria a concepção de uma modalidade específica com tais características. No Brasil, o próprio artigo $6^{\circ}$ do Código de Ética do Jornalista preconiza que "o exercício da profissão de jornalista é uma atividade de natureza social e de finalidade pública”. Entre os brasileiros, aliás, a terminologia "jornalismo cívico" carece de melhor tradução, pois a atual remete mais a patriotismo e símbolos nacionais do que à prática jornalística no sentido apregoado, enquanto "jornalismo público" conota à prática comunicativa no setor público, ou seja, estatal.

Apesar do pragmatismo dos seus propósitos iniciais, o jornalismo cívico baseia-se em um princípio amplo: o comprometimento do jornalismo e dos jornalistas com o agendamento de problemas sociais, políticas públicas e ações para combatê-los e também com a busca de solução das questões reportadas pela mídia. A idéia é que os veículos atraiam mais audiência, através da abordagem humanizada dos fatos e da oferta de informações capazes de instigar e interferir no cotidiano do público.

Christoffoletti e Puff (2004) defendem que a modalidade consiste em conjunto de estratégias para provocar reflexão e mobilização de um grupo, a partir da utilização da comunidade para elaboração e seleção de pautas; da focalização da cobertura em fatos locais; da cobertura de experiências de sucesso e fracasso, de consenso e conflito, de fatos positivos e negativos; da busca pelo aprofundamento das discussões; da indicação de soluções de problemas; da utilização de pessoas comuns da comunidade como fontes exclusivas, em substituição inclusive ao princípio da "lei das três fontes"; da adoção de recursos literários como o diálogo, com o objetivo de sensibilizar, emocionar; do trato "humanizado" das informações para atrair leitores e aproximar a atividade do público; e da junção do 
jornalismo informativo e prestação de serviços. Ao contrário do jornalismo comunitário, pode surgir e ser desenvolvido pela iniciativa privada, embora seja voltado e envolva diretamente a comunidade no processo produtivo.

Em síntese, seriam inerentes à modalidade a interação entre o público e o jornalista; a cobertura permanente e sistemática de questões de interesse público; o apoio e financiamento concedidos por empresas não-jornalísticas a coberturas de tais temáticas; o desenvolvimento pelos veículos de projetos permanentes para difusão de temas de relevância social; o envolvimento do jornalista com projetos de assistência social; e a sistemática prestação de serviços. Logo, ela implica no exercício do advocacy, ou seja, de lobby para o agendamento, a discussão e a defesa de questões de interesse público e idéias emancipatórias que assegurem melhor da qualidade de vida à população.

No Brasil, a reação da mídia às demandas decorrentes da eclosão do terceiro setor e voluntariado e a adoção de princípios do jornalismo cívico são assistemáticas e lentas (Martins da Silva et alli, 2002), restringindo-se, praticamente, a organizações não-governamentais. Surgem, no entanto, novas iniciativas inclusive na Bahia: a) a pesquisa sobre experiências com JC pela UnB (Universidade de Brasília) e por outras instituições brasileiras; b) a ação de grupos direcionados ao monitoramento e estímulo da mídia e dos jornalistas para a cobertura responsável e sistemática tanto da pauta de reivindicações desta "nova onda" quanto do cotidiano das grandes cidades, em especial das classes com baixo poder aquisitivo, a exemplo da Agência de Notícias dos Direitos da Infância (Andi) e sua rede de associados; c) a oferta de cursos, oficinas e disciplinas curriculares para a formação/capacitação de profissionais para a abordagem do tema.

Em Salvador, parte do trabalho da Rede Bahia ${ }^{4}$ pode ser caracterizada como de jornalismo cívico ${ }^{5}$. O jornal do grupo, o Correio $d a$ Bahia, encarta cadernos especiais sobre responsabilidade social e voluntariado em suas edições; a TV Salvador, emissora de canal fechado, mantém em sua programação a atração Por um Mundo Melhor, sobre cidadania, direitos humanos, voluntariado etc.; a TV Bahia, retransmissora da Rede Globo, veicula gratuitamente matérias jornalísticas e VTs publicitários sobre organizações sem fins lucrativos e campanhas sociais, e organiza eventos sociais e de arrecadação de alimentos, entre outras ações.

Ao final dos anos 1990, atores sociais soteropolitanos ligados ao terceiro setor começaram a perceber a importância do capital midiático para o seu desenvolvimento e fortalecimento e passaram a adotar estratégias de persuasão/coerção dos jornalistas e da mídia para publicização do seu discurso e das suas ações, sob a justificativa de facilitar a inserção das questões sociais na mídia e atenuar

${ }^{4} \mathrm{O}$ grupo é o maior conglomerado de comunicação do Nordeste, controla mais de 20 empresas - incluindo as seis televisões retransmissoras da Rede Globo no Estado e o jornal Correio da Bahia - e pertence à família do senador Antonio Carlos Magalhães.

${ }^{5}$ Adotando-se a classificação de Luiz Martins: "O civic journalism (...) se baseia no princípio de que a missão do jornalismo e dos jornalistas não se limita aos fatos e às notícias, exigindo engajamentos nas soluções dos problemas reportados e noticiados, no caso, problemas sociais e suas correspondentes políticas públicas”. Martins, 2005. 
os problemas do processo produtivo dos veículos. Podem ser ressaltadas, por exemplo, as atuações da Cipó Comunicação Interativa, que promove sistematicamente a cobertura de questões relacionadas à criança e ao adolescente através da capacitação e orientação das fontes e de jornalistas; do Grupo Gay da Bahia, responsável por ações esporádicas como a organização de manifestos públicos e divulgação de cartas abertas, principalmente reativas, em relação a publicações "ofensivas" aos homossexuais; e do Movimento dos Trabalhadores Sem-terra (MST), que investe no agendamento da mídia a partir da conversão do discurso pró-reforma agrária em ações como a "invasão" de áreas públicas e latifúndios.

Os principais efeitos disso são a inclusão das idéias e ações da sociedade civil organizada na agenda diária da mídia; o incremento do volume de matérias com abordagem sobre o terceiro setor e as causas sociais nos jornais locais"; a sensibilização para a "responsabilidade ética" ou o constrangimento dos jornalistas, pressionados muitas vezes até dentro das redações com visitas e distribuição de material político e ideológico; o envolvimento pessoal do jornalista com a militância (até por manter dupla jornada de trabalho, na empresa de comunicação e na assessoria de comunicação dos manifestantes) e até sua autocensura; o fortalecimento do jornalismo como prestador de serviços; a visão da mídia como "quarto poder"; e a utilização estratégica das pautas dos ativistas para desvirtuar atenções ou consolidar as próprias posições dos veículos.

O estadunidense Jay Rosen (apud Traquina, 2003: 180-181) considera que o jornalismo cívico apropria-se de uma série de procedimentos, diversos daqueles comumente utilizados na práxis jornalística. Estão entre os quais o envolvimento do cidadão comum no processo de elaboração da publicação; a consulta e valorização de fontes oficiosas e testemunhas, em detrimento da costumeira exclusividade concedida às fontes oficiais; e a valorização do espírito crítico do jornalista, que passa a ser considerado como um ator político de relevância na sociedade.

Por conseguinte, conflita com pilares do jornalismo moderno ${ }^{7}$, como a busca da neutralidade e objetividade, ancorados na dissociação entre informação e opinião, na profissionalização das redações, na apuração de múltiplas versões dos fatos e na padronização dos procedimentos produtivos com a obediência a normas técnicas (entre as quais, a pirâmide invertida e o lead) e a adoção de critérios de noticiabilidade para seleção e hierarquização dos fatos noticiados.

Todavia, somente a tentativa de caracterização de uma modalidade direcionada à promoção da justiça social e ao exercício da cidadania, por si, já cumpre relevante papel para a comunicação, a despeito de ela ser controversa e ter várias implicações na sua operacionalização. A "invenção" do conceito jornalismo cívico provoca a reflexão de profissionais e es-

${ }^{6}$ Consultar resultado total das pesquisas desenvolvidas pela Cipó/Rede Andi.

${ }^{7}$ Sobre isso, consultar Abreu, 2002; e Guerra, 2003. 
tudantes sobre sua prática e sobre a necessidade de diálogo e desenvolvimento de instrumentos para participação da comunidade na feitura das publicações, de exploração de fatos importantes para a população e de comprometimento dos veículos e dos jornalistas com seu público. E, ainda, exige mudanças no modus operandi da mídia, a reavaliação da sua linguagem e o reposicionamento de profissionais de comunicação frente ao novo cenário.

\section{Jornalismo cívico no jornal de rua}

O Aurora da Rua tornou-se singular no cenário nacional porque, de forma pioneira, assegura a participação de sem-teto tanto na produção quanto na distribuição, como co-autores do conteúdo e vendedores para sustentação da iniciativa e sua própria autonomia financeira, como co-responsáveis pela autosustentação do projeto e pelo redirecionamento da própria vida com apoio mútuo. É um componente relevante do êxito da comunidade da Trindade, assemelhando-se com propostas implementadas em outros países ${ }^{8}$ e, por outro lado, distinguindo-se pela participação articulada dos atores sociais beneficiários no seu processo de crescimento.

Com definições e aplicações diferenciadas nas ciências sociais, a palavra "participação" é tomada aqui como sinônimo de termos como colaboração, cooperação, contribuição, ajuda e envolvimento e, portanto, exige a partilha de objetivos (Estivill; Aires, 2006:13), a discussão de estratégias, o sentimento de pertencimento a um grupo e a co-gestão. Pressupõe que, de forma voluntária, as pessoas assumam identidade coletiva, a fim de defender ideais comuns e desenvolver ações conjuntas para atender às suas demandas, como ocorre com o tablóide de Salvador.

Além da afinidade com as proposições democráticas que tomam corpo no Brasil desde os anos 1970, pautadas na responsabilidade e justiça social, o jornal soteropolitano promove a reflexão e mobilização da população de rua e sobre ela, a partir da aplicação de proposições do chamado jornalismo cívico. Como já descrito acima, ele propicia a ingerência da comunidade na elaboração e seleção de pautas, enquadra principalmente fatos locais e positivos e negativos, utiliza pessoas comuns como fontes e recursos literários, busca "humanizar" as informações e prestar serviços. É feito pela, sobre e para os sem-teto. Advoga por este grupo social marginalizado, por meio da interação com o outro, da problematização de questões de interesse e importância para o público, da prestação de serviços e do envolvimento do profissional do jornalista com a assistência social. Em síntese, estimula o exercício da cidadania.

${ }^{8}$ A Associação Amigos da Praça Grande, da província de Bolonha (Itália), por exemplo, surgiu a partir da publicação do primeiro jornal de rua da Europa, o Pizza Grande, e, a posteriori, também passou a propiciar trabalho, renda e uma série de serviços a sem-teto. 


\section{Referências}

ABREU, Alzira Alves de. A Modernização da Imprensa (1970-2000). Rio de Janeiro: Jorge Zahar Editor, 2002.

AURORA da Rua. Site oficial. Salvador, 2007. Disponível em http://www.auroradarua.org.br/jornal.php , acesso em 22/12/2007.

BRIGHAM, Ciro. Trindade do amor. In Correio Repórter. Salvador: Correio da Bahia, 25 mar. 2007.

BRUM, Eliane. O olho na rua: revista de sem-teto completa dois anos na reconstrução da identidade perdida. In: Revista Época. São Paulo: Globo, 2004. Disponível em revistaepoca.globo.com/Revista/Epoca/0,,EDG65694-6014,00. html. Acesso em 20 dez. 2007a.

BRUM, Eliane. A primeira voz marginal: o Boca de Rua, feito por sem-teto de Porto Alegre, foi o pioneiro no Brasil. In: Revista Época. São Paulo: Globo, 2004. Disponível em revistaepoca.globo.com/Revista/Epoca/0,EDG656946014,00.html. Acesso em 20 dez. 2007b.

CANTARINO, Carolina. A organização internacional dos moradores de rua. In Ciência e Cultura v. 57, n 1 . São Paulo: Sociedade Brasileira para o Progresso da Ciência, Universidade Estadual de Campinas. jan.-mar. 2005. Disponível em cienciaecultura.bvs.br/scielo.php?pid=S0009-67252005000100003 \&script=sci_arttext. Acesso em 20 dez. 2007.

CELESTINO, Mônica. Anotações sobre a cobertura do terceiro setor e da área social na Rede Bahia. Rio de Janeiro: XXVIII Congresso da Intercom, Núcleo Comunicação para Cidadania, set. 2005.

COSTA, Marcelo J. da. A voz que ecoa da rua. In Blog da Rua. Rio de Janeiro, 27 mar. 2007. Disponível em http://blogdarua.blogspot.com/2007/03/voz-queecoa-da-rua.html. Acesso em 14 jan. 2008.

CHISTOFOLETTI, Rogério; PUFF, Jefferson. Direitos Humanos nos Jornais: um caso de tratamento epidérmico. IV Encontro de Núcleos de Pesquisa da Intercom/ XXVII Congresso de Ciências da Comunicação, Porto Alegre (RS), ago.-set. 2004.

ESTIVILL, Jordi; AIRES, Sérgio (coord.). Pequenas experiências, grandes esperanças! Porto, Portugal: Rede Européia Anti-Pobreza, Ministério do Trabalho e da Segurança Social, 2006.

GUERRA, Josenildo Luiz. O Nascimento do Jornalismo Moderno - uma discussão sobre as competências profissionais, a função e os usos da informação jornalística. Anais do $26^{\circ}$ Congresso Brasileiro de Ciências da Comunicação. Belo Horizonte-MG, 09/2003. São Paulo: Intercom, 2003. Disponível em reposcom.portcom.intercom.org.br/bitstream/1904/4406/1/NP2GUERRA.pdf. Acesso em 5 fev. 2008.

INTERNATIONAL Network of Street Papers. Glasgow (Escócia). Site oficial. Disponível em http://www.street-papers.com/. Acesso em 22 dez. 2007.

LIMA, Jaiane. O Peregrino da Trindade. In Espaço Reservado II. Salvador, 5 dez. 2007. Disponível em http://jailima.wordpress.com/2007/12/05/o-peregrino-da-trindade/. Acesso em 27 dez. 2007.

PESQUISA LEVANTA dados sobre população de rua. In: A Tarde, 1 out. 2007. Disponível em www.atarde.com.br/cidades/noticia.jsf?id=794133. Acesso em 20 dez. 2007. 
REVISTA Ocas. São Paulo, Rio de Janeiro: Organização Civil para Ação Social (Ocas). Site oficial. Disponível em http://www.ocas.org.br. Acesso em 3 jan. 2008.

MARTINS DA SILVA, Luiz. Civic Journalism - Um gênero que o Brasil começa a conhecer. Site http://observatorio.ultimosegundo.ig.com.br/artigos/ jd290520023.htm. Acesso em 23 ago. 2005.

MARTINS DA SILVA, Luiz et al. Jornalismo público: o social como valor-notícia. Universidade de Brasília: Brasília, 2002.

TRAQUINA, Nelson; MESQUITA, Mário (org.). Jornalismo Cívico. Lisboa: Livros Horizonte, 2003.

TRAQUINA, Nelson. O Estudo do Jornalismo no Século XX. São Leopoldo (RS): Unisinos, 2003.

\section{Fonte oral}

PEREGRINO, Henrique. Depoimento concedido a estudantes e professores de jornalismo do Centro Universitário da Bahia - FIB, em 23 de novembro de 2007.

Recebido em 30 de agosto de 2008 Aprovado em 25 de outubro de 2008 